TERRA. Revista de Desarrollo Local e-ISSN: 2386-9968

Número 7 (2020), 299-304

DOI 10.7203/terra.7.19294

IIDL - Instituto Interuniversitario de Desarrollo Local

\title{
Buenas Prácticas de la Agencia de Desarrollo Local de Alicante en materia de emprendimiento
}

\section{Ester González Herreros}

Técnica en Promoción Económica. Agencia de Desarrollo Local de Alicante, Organismo Autónomo del Ayuntamiento de Alicante (España)

ester.gonzalez@ua.es

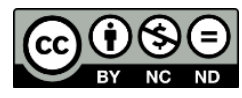

Esta obra se distribuye con la licencia Creative Commons

Reconocimiento-NoComercial-SinObraDerivada 4.0 Internacional 


\section{SECCIÓN EXPERIENCIAS Y BUENAS PRÁCTICAS}

\section{Buenas Prácticas de la Agencia de Desarrollo Local de Alicante en materia de emprendimiento}

Resumen: La mayoría de las empresas necesita algún tipo de apoyo en algún momento de su desarrollo. Un ejemplo de estos lugares en nuestro país, desde el año 2006, son los Puntos de Atención al Emprendedor (PAE). En el municipio de Alicante, a través de la Agencia de Desarrollo Local, se comenzó a dar el servicio PAE en 2013. Por otro lado, la formación en materia de creación de empresas es otro servicio que da la Agencia de Desarrollo Local, impartiendo cursos y talleres orientados a la ayuda de la creación de negocios.

Palabras clave: emprendimiento, formación, emprendedores, asesoramiento.

Recibido: 15 de diciembre de 2020

Devuelto para revisión: -

Aceptado: 15 de diciembre de 2020

Referencia / Citation:

González, E. (2020). Buenas Prácticas de la Agencia de Desarrollo Local de Alicante en materia de emprendimiento. TERRA. Revista de Desarrollo Local, (7), 299-304. DOI 10.7203/terra.7.19294 


\section{EL APOYO A LA CREACIÓN DE EMPRESAS}

La mayoría de las empresas necesita algún tipo de apoyo en algún momento de su desarrollo. Un ejemplo de estos lugares en nuestro país, desde el año 2006, son los puntos PAIT (Punto de Asesoramiento e Inicio de Tramitación), que posteriormente modificaron su denominación y actualmente son conocimos como Puntos de Atención al Emprendedor (PAE). La información referente a la tramitación se puede obtener de la página web: www.circe.es, del Ministerio de Industria. En los puntos PAE se ofrece la posibilidad de realizar los trámites de constitución y puesta en marcha de un autónomo y de una Sociedad Limitada por medios telemáticos, con lo que se evitan así desplazamientos al emprendedor y, en consecuencia, se produce un ahorro sustancial de tiempos y costes. El emprendedor debe dirigirse a un PAE en el que se le asesorará en todo lo relacionado con la definición de su proyecto empresarial, y se le permitirá iniciar los trámites de constitución y puesta en marcha de éste.

Si lo que se desea es darse de alta como autónomo, se ha de acudir, previa cita al Punto $\mathrm{PAE}$, con los documentos requeridos y en la sesión presencial, se procede a tramitar el alta, salvando así el trámite de acudir a la Delegación de Hacienda y a la Tesorería General de la Seguridad Social para realizar dicha alta, agilizándose y facilitándole trámites al interesado.

En el caso de la constitución de la Sociedad Limitada con el procedimiento telemático, el emprendedor sólo tiene que ir presencialmente al PAE y al notario, evitando así desplazarse para realizar el resto de los trámites y sin necesidad de utilizar formularios en papel. En el PAE, el emprendedor deberá suministrar la información necesaria para que un técnico cumplimente el Documento Único Electrónico (DUE), aportando la documentación que se le exija. La cita con el notario se obtiene de forma inmediata mediante una comunicación en tiempo real con el sistema de la Agenda Notarial, obteniéndose los datos del notario y la fecha y hora de la cita. El Documento Único Electrónico, una vez cumplimentado, inicia la tramitación telemática. A partir de este momento, el sistema de tramitación telemática envía a cada organismo interviniente en el proceso, la parte del DUE que le corresponde para realizar el trámite de su competencia.

Por tanto, de forma esquemática, los trámites a realizar y facilitados por el PAE son:

1. Obtener la documentación necesaria para poder comenzar el trámite.

2. Ir al PAE para rellenar el DUE y concretar la cita con el notario.

3. Ingresar en una cuenta bancaria el capital social.

4. Ir a la notaría con el certificado del ingreso y recoger la escritura.

5. El CIF definitivo lo recibirá en su domicilio.

Los emprendedores, hoy en día, buscan disponer de una formación adecuada y adaptada a las necesidades de creación de nuevas empresas, ya que nos encontramos en un mundo muy competitivo a todos los niveles.

Las Agencias de Empleo y Desarrollo Local (ADLs) han ido surgiendo en función de las necesidades que los Entes locales, en particular, los Ayuntamientos, han apreciado en materia de crecimiento y desarrollo local. Con su creación se ha querido cubrir el hueco en materia de empleo y emprendimiento que se había producido en cada localidad o grupo de ellas (caso de los Consorcios que agrupan pequeños municipios). 
Por motivo de la crisis económica de comienzos del siglo XXI, las ADLs han visto modificada e incrementada la cifra de emprendedores que buscaban asesoramiento y, por ello, han tenido que adaptarse a las nuevas necesidades del mercado. Han surgido personas que, conociendo de forma profunda un sector, nunca antes se habían planteado ser emprendedores y que tampoco habían recibido una formación previa en estas materias.

\section{ESPECIAL REFERENCIA A LA ADL DEL MUNICIPIO DE ALICANTE EN MATERIA DE CREACIÓN DE EMPRESAS}

La ADL del municipio de Alicante fue creada en el año 2000 vía Acuerdo Marco para el Desarrollo Económico y el Empleo de la ciudad de Alicante, articulado por la Concejalía de Empleo y Fomento del Ayuntamiento de Alicante. Desde sus inicios ha tenido entre sus objetivos primordiales la creación y el mantenimiento de empresas en su municipio, para lo que se ha dotado de los instrumentos adecuados. Podemos destacar poco después de sus inicios y como primer programa europeo solicitado y concedido por la Unión Europea a la ADL, el Programa denominado "Alicante Emprende”, enmarcado dentro del Pilar II de la iniciativa EQUAL "Fomento del espíritu emprendedor y la creación de nuevas empresas”, cuyo objetivo general era contribuir a la consolidación de la cultura favorable a la innovación, el espíritu emprendedor y la creación de empresas en el municipio de Alicante; en especial, en el caso de los jóvenes y demandantes de empleo, empresas de reciente creación y mujeres emprendedoras.

El programa fue ejecutado durante 2003-2004 por una Agrupación de Desarrollo integrada por la Consellería de Economía, Hacienda y Empleo de la Generalitat Valenciana, la ADL de Alicante, la Asociación de Jóvenes Empresarios de la provincia de Alicante (JOVEMPA), la Confederación Empresarial de la provincia de Alicante (COEPA) y la Asociación de Empresarias y Profesionales de Alicante (AEPA); y en cooperación transnacional con el Centro de Empresas e Innovación del Algarve (Portugal) y la Cámara de Comercio e Industria de Brasov (Rumanía). La financiación del programa, con un coste total de 1.802.000 euros, corrió a cargo en un 75 \% del Fondo Social Europeo de la Unión Europea, en un 10 \% de la Consellería de Economía, Hacienda y Empleo y en un 15 \% de la Agrupación de Desarrollo. La Iniciativa Comunitaria EQUAL fue un instrumento ampliamente utilizado por parte de diferentes Agencias Locales de Desarrollo y otros organismos relacionados con el Desarrollo Local para la puesta en marcha de proyectos dirigidos a dicho ámbito.

Vamos a aportar la información relativa a atención a emprendedores de los últimos cinco años (2012-2016) registrada en la ADL de Alicante. Se ha de indicar que para calcular dicha atención de forma agregada, se ha tenido en cuenta la atención realizada en dos centros de trabajo de la agencia, las oficinas centrales ubicadas en el Edificio Puerta Ferrisa de Alicante y las oficinas situadas en Zona Norte de Alicante (Edificio Tossalet). Además, incluimos la colaboración que presta JOVEMPA en la atención a emprendedores, por la existencia de convenido firmado años atrás con dicha entidad. Se aporta también la información referente a las empresas creadas en este período, derivadas de la atención realizada (Tabla 1).

También se puede aportar de la ADL de Alicante la información de las altas realizadas en el punto PAE de que se dispone en las oficinas centrales (Edificio Puerta Ferrisa). Dicha información nos aporta datos recientes de los Autónomos y Sociedades Limitadas dados de alta por parte del Punto PAE de la capital alicantina (Tabla 2). 
Tabla 1. Atención a emprendedores de 2012 a 2016 en la ADL de Alicante

\begin{tabular}{|c|c|c|}
\hline Año & $\mathbf{N}^{\mathbf{0}}$ de personas & Empresas creadas \\
\hline 2012 & 1.147 & 68 \\
\hline 2013 & 1.083 & 33 \\
\hline 2014 & 1.333 & 154 \\
\hline 2015 & 791 & 110 \\
\hline 2016 & 864 & $\mathbf{4 7 8}$ \\
\hline Total & $\mathbf{4 . 4 2 7}$ & $\mathbf{4 8}$ \\
\hline
\end{tabular}

Fuente: elaboración propia a partir de datos de la ADL de Alicante.

Tabla 2: Creación de empresas a través del Punto PAE de Alicante

\begin{tabular}{|c|c|c|c|c|}
\hline Año & Autónomos & SL & SLNE & TOTAL \\
\hline 2013 & 14 & 3 & 0 & 17 \\
\hline 2014 & 49 & 6 & 0 & 55 \\
\hline 2015 & 15 & 77 & 0 & 92 \\
\hline 2016 & 37 & 63 & 1 & 101 \\
\hline Total últimos 4 años & 115 & 149 & 1 & 265 \\
\hline
\end{tabular}

Fuente: elaboración propia a partir de datos de la ADL de Alicante.

\section{FORMACIÓN SOBRE CREACIÓN DE EMPRESAS EN LA ADL DEL MUNICIPIO DE ALICANTE}

Podemos detallar la formación que se viene impartiendo en el Centro de Emprendedores de la ADL de Alicante y, con ello, evidenciamos las ventajas que tiene para los potenciales emprendedores el acudir a los cursos y talleres de creación de empresas. A continuación reflejamos la asistencia de los últimos cinco años, por parte de los emprendedores, a los Cursos ("De la idea a la puesta en marcha") y Talleres ("Crea tu empresa”) de creación de empresas (Tabla 3). Asimismo, la ADL de Alicante imparte un programa muy completo de actividades trimestrales dirigidas a emprendedores y empresarios que necesiten adquirir nuevos conocimientos en materia empresarial, se trata de charlas de entre cuatro y ocho horas de duración, lo que viene en llamarse "píldoras" de conocimiento, de manera que por su concreción y duración resulten atractivas para las personas interesadas.

Tabla 3: Asistentes por cursos y talleres de creación de empresas 2012-2016

\begin{tabular}{|c|c|}
\hline Año & $\mathbf{N}^{\mathbf{0}}$ de personas \\
\hline 2012 & 435 \\
\hline 2013 & 445 \\
\hline 2014 & 414 \\
\hline 2015 & 284 \\
\hline 2016 & 185 \\
\hline Total últimos 5 años & 1.763 \\
\hline
\end{tabular}

Fuente: elaboración propia a partir de datos de la ADL de Alicante. 
A continuación detallamos la totalidad de actividades en materia de formación empresarial (2012-2016) que se realiza en el Centro de Emprendedores de la ADL. Esta formación abarca todo el año y las materias son tan variadas como la innovación empresarial, el marketing, el coaching, las ventas, etc., todo un recorrido por la formación necesaria para desenvolverse en el ámbito empresarial (Tabla 4).

Tabla 4: Actividades del centro de emprendedores 2012-2016

\begin{tabular}{|c|c|c|}
\hline Año & $\mathbf{N}^{\mathbf{0}}$ de actividades & $\mathbf{N}^{\mathbf{0}}$ de asistentes \\
\hline 2012 & 87 & 3.602 \\
\hline 2013 & 65 & 2.813 \\
\hline 2014 & 153 & 4.088 \\
\hline 2015 & 52 & 2.569 \\
\hline 2016 & 70 & 1.720 \\
\hline Total últimos 5 años & 427 & 14.792 \\
\hline
\end{tabular}

Fuente: elaboración propia a partir de datos de la ADL de Alicante.

Como conclusión a lo detallado en materia de punto PAE y a la formación para emprendedores, podemos señalar que todos los esfuerzos que se realicen en materia de asesoramiento y formación de los mismos serán pocos en pro de que nuestra economía crezca y se diversifique gracias a la creación de nuevas empresas que mejoren nuestro tejido empresarial. 